\title{
СОПРЯЖЕННОЕ РАЗВИТИЕ КООРДИНАЦИОННЫХ СПОСОБНОСТЕЙ В ВОЛЕЙБОЛЕ ГЛУХИХ
}

\section{CONJUGATE DEVELOPMENT OF COORDINATION ABILITIES IN THE WILL OF THE DEAF}

\section{Schneider}

Summary: The purpose of the study presented in this article was to substantiate the effectiveness of the conjugate method in deaf volleyball. It is assumed that the conjugate method, implemented in the training of deaf and hard of hearing athletes, will increase the level of their coordination abilities and at the same time optimize the educational and training process. A set of exercises with the use of a conjugate method for specialized warm-up of deaf and hearing impaired, volleyball players has been developed and tested, the dynamics of the development of coordination abilities of deaf and hearing impaired, athletes has been investigated.

Keywords: coupled method, development of coordination abilities, specialized warm-up in volleyball, especially deaf and hard of hearing athletes.

\author{
Шнейдер Виктор Юдович \\ дочент, заслуженный тренер России, Сургутский \\ государственный университет, Сургут \\ shv.53@mail.ru
}

Аннотация: Целью исследования, представленного в настоящей статье, явилось обоснование эффективности сопряженного метода в волейболе глухих. Предполагается, что сопряженный метод, реализуемый в тренировке глухих и слабослышащих спортсменов, позволит повысить уровень их координационных способностей и одновременно оптимизировать учебно-тренировочный процесс. Разработан и апробирован комплекс упражнений с использованием сопряженного метода для специализированной разминки глухих и слабослышащих волейболистов, исследована динамика развития координационных способностей глухих и слабослышащих спортсменов.

Ключевые слова: сопряженный метод, развитие координационных способностей, специализированная разминка в волейболе, особенности глухих и слабослышащих спортсменов.
$\mathrm{O}$ дной из важнейших задач, стоящих перед тренерами-преподавателями, является развитие двигательной координации как фундамента для создания благоприятных возможностей более динамичного освоения практического материала и создания двигательного потенциала для повышения мастерства в избранном виде спорта [1]. Отсутствие должного внимания со стороны спортивных педагогов к вопросу совершенствования координационных способностей и качеств детей и подростков приводит к тому, что юные спортсмены недостаточно владеют своим телом, в значительной степени нерационально управляют своими движениями, плохо ориентируются в пространстве, неточно взаимодействуют с внешними предметами [2]. Интенсивная и многоступенчатая координационная подготовка оказывает существенное влияние на качество и динамику овладения новыми движениями [6], но при этом в работе с глухими и слабослышащими спортсменами встает вопрос экономии времени, в связи со сложностью коммуникации при обучении, поэтому главный акцент в работе тренеры делают на кондиционную, техническую и тактическую подготовку.

Перенос методов подготовки квалифицированных спортсменов в адаптивный спорт эффект дает не всегда, и поэтому недопустим без переработки методики под недостаточно подготовленный контингент. Специализированная разминка позволяет не только подготовить организм волейболиста к освоению техники и тактики игры, но и позволяет одновременно с подготовкой к основной части занятия, развивать и совершенствовать координационные способности и специальную ловкость спортсменов.

Целью исследования явилось обоснование эффективности сопряженного метода в тренировке глухих и слабослышащих волейболистов. Предполагается, что сопряженный метод, реализуемый в тренировке глухих и слабослышащих спортсменов в виде специализированной волейбольной разминки, позволит повысить уровень их координационных способностей (КС) и одновременно оптимизировать учебно-тренировочный процесс.

Были поставлены задачи исследования:

1. Изучить состояние вопроса по данным научнометодической литературы;

2. Определить исходный уровень развития координационных способностей у глухих и слабослышащих волейболистов;

3. Разработать и апробировать комплекс упражнений с использованием сопряженного метода для специализированной разминки глухих и слабослышащих волейболистов;

4. Определить итоговый уровень развития координационных способностей глухих и слабослыша- 
щих волейболистов и провести сравнительный анализ динамики показателей координационных способностей глухих и слабослышащих волейболистов в экспериментальной и контрольной группах.

В работах, посвященных КС ранее использовался термин «ловкость» $[2,10]$, который встречается и в современных исследованиях. Кроме того, используются и другие терминологические понятия: «способность управлять движениями», «общее равновесие», а также более узкие: «мелкая моторика», «ручная координация», «прыжковая ловкость» «динамическое равновесие», и др. $[7,8,11]$.

Критерием сформированности координационных способностей человека служит его умение решать разнообразные двигательные задачи с высокой эффективностью (быстро и точно). Эти умения проявляются в повседневных бытовых и спортивных двигательных навыках. Именно поэтому формирование, развитие и коррекция координационных качеств у детей и подростков с такой патологией, как нарушение слуха, имеет для них значение, позволяя им лучше адаптироваться и реализоваться в социуме [3].

Координационные способности эффективно развиваются с помощью упражнений, которые предъявляют высокие требования к согласованности и упорядоченности двигательных актов, синергии их в единую системy.

Эти упражнения должны отвечать следующим требованиям:

- достаточная координационная трудность для спортсмена;

- отличие от стандартных, часто применяемых действий;

- большое разнообразие форм, вариативность движений и их составляющих (темпо-ритм, амплитуда, время, направление, интенсивность мышечного усилия) [8].

Системообразующим элементом здесь является высокая различающая способность по отношению ко всем параметрам выполняемого движения.

Способности к тонкому дифференцированию отдельных признаков движения в значительной степени детерминируются уровнем развития восприятия и ощущений различной модальности (тактильные, зрительные и, прежде всего, мышечно-двигательные).

По мере совершенствования этих способностей формируются представляющие собой комбинацию восприятий и ощущений специализированные чувства: «чувство пространства», «чувство времени», «чувство мяча», «чув- ство прилагаемой силы» и т.п. Уровень развития специализированных чувств, определяет динамику освоения технико-тактического арсенала и эффективность его применения, а также способности к управлению двигательной деятельностью и отдельными движениями в целом.

Положение о многоуровневом строении психомоторной деятельности человека обосновано Н.А. Бернштейном. По его мнению, это является основной причиной, по которой один ребенок в результате тренировок, а то и без них, показывает лучший результат в циклических видах спорта, другой более успешен в спортивных играх, третий опережает сверстников в упражнениях, связанных с точностью движений и т.д. $[4,5]$.

Многолетние исследования КС позволили сделать вывод, что различные показатели разных КС в подавляющем большинстве случаев не коррелируют между собой и достоверно не связаны с уровнем показателей перцептивных, сенсомоторных и других психофизиологических функций. Чтобы обеспечить более высокий уровень КС, недостаточно развития одной какой-то функции, даже если она имеет высокие показатели развития. Необходим высокий уровень развития всех функций, или определенного их сочетания [5].

Средства развития КС должны отвечать определенным требованиям, основными являются следующие:

- преодоление трудностей по координации движений;

- рациональность выполнения;

- точность и быстрота в сложной обстановке;

- соответствие модели (эталону) двигательного действия;

- находчивость при выборе способа действий;

- новизна и необычность условий исполнения;

- выполнение вариативных, измененных движений.

При дефиците тренировочного времени для сопряженного воздействия на координацию и кондицию можно комбинировать обще-подготовительные упражнения и специально-подготовительные упражнения в различных сочетаниях. Например, попеременное метания в мишень мячей разного веса; прыжки в полную силу или вполовину от максимального усилия, прыжки с поворотами на определенный угол, чередование бега по прямой в сочетании с изменением направления или скорости и т.д.

В модифицированном виде сочетание обще-подготовительных и специально-подготовительных координационных упражнений небольшой интенсивности можно использовать при проведении специализированной разминки, решая сразу задачи растяжки, разогрева, настроя и развития КС, кондиций и овладения элементами техники. 
Если проводить такую разминку сопряженным методом в игровой форме, то эффективность ее использования может многократно возрастать.

Метод направленного сопряжения имеет хорошие перспективы в адаптивном спорте, где существует острая проблема нехватки времени в тренировке на обучение и совершенствование.

Кроме игрового, важное место в тренировке при совершенствовании КС занимает соревновательный метод. Многие упражнения на развитие КС можно выполнять с использованием этого принципа.

Кроме того, необходимо использовать специализированные средства, оказывающие воздействие на системы, участвующие в управлении и регулировке движениями, а также получение информации о параметрах этих движений.

Такими специализированными средствами и методами являются видео для анализа техники движений; идеомоторные упражнения, лидирование, применение тренажеров и технических средств, направленных на тренировку необходимых КС, приборы, регистрирующие параметры движений, приборы биологической обратной связи (БОС), сигнализирующие об отклонении от параметров движения и т.п.

Мы проанализировали и обобщили КС и методы их развития, являющиеся наиболее важными для волейболистов в силу своего влияния на характер специфической двигательной деятельности в условиях игры.

Для волейболиста важны следующие координационные качества:

Способность к ориентированию, способность к дифференцированию параметров движений, способность к перестроению двигательных действий, способность к реагированию, способность к согласованию.

Способность к ориентированию в пространстве ярко проявляется в волейболе. Упражнения на ориентирование в пространстве: бег с преодолением препятствий, бег и ведение мяча по линиям, прыжки на точность и через предметы, метания в цель.

Чувство темпо-ритма показывает степень точности прилагаемого усилия, чередования напряжения и расслабления. Оно, как и любые другие КС, является специфичным, тренировать его следует в условиях, адекватных модели вида спорта. [12].

Способность спортсмена к перестроению двигательных действий ранее характеризовалась как составляющая ловкости. Сейчас она классифицируется как обобщенная КС. Она важна в спортиграх, в волейболе, в частности, в котором содержанием двигательной деятельности является быстрая и точная перестройка действий.

Для формирования этой способности служат упражнения на реагирование в изменяющихся ситуациях, где требуются антиципирующие реакции. Полезными являются упражнения на развитие интеллектуальных, перцептивных, сенсомоторных и волевых качеств и процессов.

Способность к произвольному расслаблению мышц. Координационная напряженность может возникать при совершении простых, привычᄀных движений из-за неумения расслабляться, а также по причине утомления или повышения ситуативной тревожности в стрессовой обстановке соревнований и т.д. Снять напряженность можно по-разному. Во многих случаях помогает психическая регуляция, повышающая устойчивость к стрессовым ситуациям [9].

Способность к реакции имеет большое значение в спортивных играх. В волейболе невозможно добиться успехов без достаточного уровня развития способности к реакции.

Наблюдения позволяет получить информацию о том, как спортсмен овладевает упражнениями, как координирует свои движения, как перестраивает двигательные действия при смене ситуации. Точные количественные оценки КС с помощью метода наблюдения получить нельзя. Оценивать КС можно на основании метода экспертных оценок. Наиболее подходящим является способ предпочтения (ранжирования), при котором эксперты расставляют КС оцениваемых спортсменов по рангам. Инструментальные методы дают достаточно точные количественные оценки уровня КС.

В тренировочном процессе в волейболе глухих и слабослышащих на стадии начальной подготовки все тренеры сталкиваются с проблемой нехватки времени на освоение техники. Вопрос экономии времени частично решается путем использования современных технологий обучения $[14,15,16]$.

Как было отмечено выше, для динамичного освоения техники у занимающихся нужно создать достаточную координационную базу. Но для этого тоже нужно время. Где же его взять? Выход в использовании сопряженного метода во время разминки. У большинства детей с поражением слуха уровень развития координационных способностей недостаточный.

Если в каждой тренировки во время разминки кроме растяжки включать упражнения на координацию и элементы техники, то в течение нескольких месяцев можно 
получить достаточно значительный прирост в уровне KC.

Из всех координационных способностей для освоения техники игры в волейбол на начальном этапе наиболее важна ручная координация. Специальная ловкость волейболиста тесно связана с выработкой чувства мяча, включающего качества: точное восприятие веса мяча, его упругости, инерции и скорости, а также дистанционное зрение. Эти качества вырабатываются при бросках и ловле мяча, жонглировании и балансировании. Также важна ориентировочная способность, ее можно развивать упражнениями с бросками, перемещениями и ловлей мяча, а также с помощью подвижных игр, с элементами волейбола. Эти упражнения можно включить во вторую половину разминки, в целях предупреждения травм [31].

Для людей с нарушением слуха, особенно детей, характерны различные нарушения двигательной сферы. В работах Т.В. Розановой и А.О. Костаняна эти факты объясняются тем, что «...патология слухового анализатора изменяет не только функции вестибулярного аппарата, но и функции кинестезического анализатора, который определяет особенности двигательной деятельности глухих» [3]. Исследователи отмечают, что компенсировать недостаточность каналов обратной связи в процессе обучения и развития детей с нарушением слуховой функции можно за счет сохранных функций других сенсорных систем.

При работе с глухими и слабослышащими детьми в тренировочном процессе спортивный педагог должен учитывать следующие положения:

у занимающихся детей с патологией слуха работоспособность в процессе тренировки непостоянна, и часто снижается быстрее, чем у здоровых. Ухудшение внимания и памяти (особенно двигательной) проявляются тоже значительно чаще. Латентный период двигательной реакции удлинен. Время двигательной реакции и одиночного движения увеличены. Выражены снижения способности к сохранению равновесия всех видов (как статического, так и динамического) [3].

В тренировочном процессе у глухих и слабослышащих проявляются свои особенности: необходимо постоянно поддерживать визуальный контакт, важна хорошая артикуляция, поскольку они читают по губам. Очень важен качественный показ упражнений.

Сочетание общеразвивающих упражнений с мячом и упражнений на развитие специальной ловкости составляет основное содержание специализированной разминки в волейболе. В процессе тренировки с глухими детьми нельзя отказываться от вербального общения (устная речь). Включение речи в содержании трениров- ки позволяет накапливать и осмысливать словарный запас, связанный с двигательными навыками, и положительно влияет на развитие интеллектуальной сферы ребенка с нарушением слуха.

Правильное психологически, педагогически, организационно и методически построенное занятие физической культурой компенсирует недостатки в двигательной сфере и физическом развитии глухих и слабослышащих детей.

Экспериментальное исследование проводилось на базе МБУ СП СШ «Аверс» г. Сургута в естественных условиях тренировочного процесса глухих и слабослышащих волейболистов-юношей. В исследовании принимали участие две спортивно-оздоровительные группы глухих и слабослышащих волейболистов-юношей возраста 13-17 лет в общем количестве 14 человек, которые были поделены на две подгруппы по 7 человек. Занятия проводились с обеими группами совместно. Тренировки проводились заслуженным тренером России С.Н. Руденко.

Был составлен комплекс специализированной разминки на основе сопряженного метода, включающий одновременно с типичными упражнениями разминки на растяжку и разогрев, упражнения на развитие КС.

Тестирование проводилось в начале и в конце учебного года.

Были отобраны тесты, которые по данным литературы отражают уровень общих и специальных координационных способностей волейболистов:

1. Бег к пронумерованным мячам (оченка ориентирования в пространстве).

2. Прыжок в длину с места лииом и спиной (способность к перестроению двигательного действия)

3. Бег в упоре сзади (оченка согласованности движеHuй)

4. Бросок мяча в чель, стоя спиной к иели (оченка дифферениированного мышечного усилия).

5. Комплексный координационный тест (ККТ, оченивается ловкость).

Результаты первичного тестирования позволили сравнить уровень развития КС глухих и слабослышащих волейболистов в экспериментальной группе и контрольной группе. Средние показатели КС групп достоверно не различались по первым четырем КС, а в комплексном координационном тесте уровень КС в контрольной группе был достоверно выше, чем в экспериментальной. Исходные данные групп позволили начать запланированный педагогический эксперимент.

Во время эксперимента с октября 2019г. по апрель 2020г., контрольная группа в разминке выполняла стан- 
Динамика развития координационных способностей у глухих и слабослышащих

Таблица 1. волейболистов за время эксперимента

\begin{tabular}{|c|c|c|c|c|}
\hline \multirow[t]{2}{*}{ Контрольные тесты } & \multicolumn{2}{|c|}{ Экспериментальная группа } & \multicolumn{2}{|c|}{ Контрольная группа } \\
\hline & Исходный уровень X+m & Итоговый уровень X+m & Исходный уровень X+m & Итоговый уровень X+m \\
\hline $\begin{array}{l}\text { Бег к пронумерованным } \\
\text { мячам, сек }\end{array}$ & $\begin{array}{c}26,3 \pm 0,15 \\
\text { ниже среднего }\end{array}$ & $\begin{array}{c}24,8 \pm 0,22^{*} \\
\text { высокий }\end{array}$ & $\begin{array}{c}25,8 \pm 0,26 \\
\text { средний }\end{array}$ & $\begin{array}{c}25,2 \pm 0,14 \\
\text { выше среднего }\end{array}$ \\
\hline $\begin{array}{l}\text { Прыжок в длину (соотноше- } \\
\text { ние ПДс:ПДл) }\end{array}$ & $\begin{array}{c}0,92 \pm 0,19 \\
\text { средний }\end{array}$ & 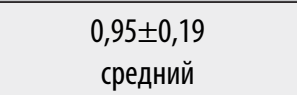 & 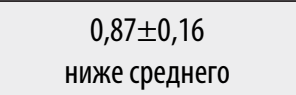 & $\begin{array}{c}0,90 \pm 0,22 \\
\text { ниже среднего }\end{array}$ \\
\hline $\begin{array}{l}\text { Бег в упоре сидя (лицом } \\
\text { вперед), сек }\end{array}$ & $\begin{array}{c}\text { 6,24 } \pm 0,58 \\
\text { ниже среднего }\end{array}$ & 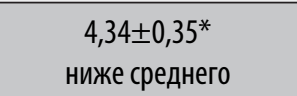 & $\begin{array}{c}\text { 6,12 } \pm 0,18 \\
\text { ниже среднего }\end{array}$ & $\begin{array}{c}5,68 \pm 0,29 \\
\text { низкий }\end{array}$ \\
\hline $\begin{array}{l}\text { Бросок мяча в цель, стоя } \\
\text { спиной к цели, баллы }\end{array}$ & $\begin{array}{c}8,1 \pm 0,07 \\
\text { ниже среднего }\end{array}$ & $\begin{array}{c}11,2 \pm 0,13^{*} \\
\text { выше среднего }\end{array}$ & 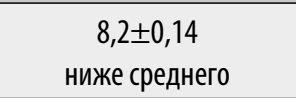 & $\begin{array}{c}8,6 \pm 0,09^{*} \\
\text { средний }\end{array}$ \\
\hline $\begin{array}{l}\text { Комплексный координаци- } \\
\text { онный тест, сек }\end{array}$ & $\begin{array}{c}23,5 \pm 0,59 \\
\text { низкий }\end{array}$ & $\begin{array}{c}18,3 \pm 0,38^{*} \\
\text { высокий }\end{array}$ & $\begin{array}{c}21,3 \pm 0,42 \\
\text { средний }\end{array}$ & $\begin{array}{c}20,5 \pm 0,33 \\
\text { выше среднего }\end{array}$ \\
\hline
\end{tabular}

* - изменения достоверны $\mathrm{p}<0.05$

дартный комплекс упражнений, предусмотренный типовой программой для ДЮСШ, включающий растяжку, статические и динамические упражнения для основных групп мышц, перемещения и беговые упражнения.

Для экспериментальной группы была составлена специализированная разминка на основе сопряженного метода, т.е. одновременно с типичными упражнениями разминки на растяжку и разогрев, выполнялись упражнения, направленные на развитие КС, все упражнения в разминке выполнялись сразу с мячом.

Сравнительные результаты (средние показатели групп) тестирования координационных способностей глухих и слабослышащих волейболистов представлены в таблице 1.

\section{Выво}

1. Одной из важнейших задач, стоящих перед тренерами-преподавателями по волейболу, является развитие двигательной координации как фундамента для создания благоприятных возможностей более динамичного освоения практического материала и создания двигательного потенциала для повышения мастерства в избранном виде спорта. Данные научной литературы свидетельствуют, что интенсивная и многоступенчатая координационная подготовка оказывает существенное влияние на качество и динамику овладения новыми движениями. Специализированная разминка с использованием сопряженного метода, как средство интегральной подготовки и как педагогическая технология, направленная на оптимизацию тренировочного процесса, пока не нашла должного места в работе с глухими и слабослышащими волейболистами.

2. Уровень развития координационных способностей глухих и слабослышащих волейболистов в спортивно-оздоровительной группе МБУ СП СШ «Аверс» г. Сургута в начале эксперимента находился в диапазоне от низкого уровня до среднего. Спортсмены обследуемых групп недостаточно владели своим телом, в значительной степени нерационально управляли своими движениями, плохо ориентировались в пространстве, неточно взаимодействовали с внешними предметами (ловля и броски мячей в цель, точность передач и ударов).

3. Составлен и апробирован комплекс упражнений с использованием сопряженного метода, как средства интегральной подготовки для специализированной разминки глухих и слабослышащих волейболистов, которая позволяет одновременно с подготовкой к основной части занятия, развивать и совершенствовать координационные способности и специальную ловкость занимающихся, что создает предпосылки для более динамичного освоения техники игры в условиях дефицита времени.

4. Прослеживается положительная динамика развития уровня КС за период эксперимента. Итоговый уровень развития КС у глухих и слабослышащих волейболистов в экспериментальной группе достоверно повысился по четырем тестам из пяти: способности к ориентированию в пространстве, способности к согласованию движений, способности к дифференцированию мышечных усилий и общей координации. В контрольной группе прирост недостоверен по четырем тестам, и только по одному тесту - способности к дифференцированию мышечных усилий - достоверный. В тесте на способность к перестроению движений изменения за время эксперимента недостоверны в обеих группах, что свидетельствует о недостаточности средств для развития данной КС. 


\section{ЛИТЕРАТУРА}

1. Бальсевич В.К. Физическая культура для всех и для каждого. - М.: ФкиС, 1988. - 264с.

2. Беймен В.Р. Искусство ловкости. - Брест, 1997. -76с.

3. Бабенкова Р.Д., Трофимова Г.В. Занятия по развитию движений у детей с нарушением слуха в школьных учреждениях // Методические рекомендации. - M., 1973. -32 .

4. Бернштейн Н.А. Очерки по физиологии движений и физической активности. - М.: Наука, 1990. - 4966.

5. Бернштейн Н.А. 0 ловкости и ее развитии. - М.: Физкультура и спорт, 1991. - 228 с.

6. урьев А.А. Методика специальной физической подготовки для повышения координационных способностей и вестибулярной устойчивости волейболистов с учетом их морфофункциональных особенностей. Автореферат на соискание ученой степени кандидата педагогических наук. - Малаховка, 2010 $-151 c$.

7. Голомазов С.В. Теоретические основы биомеханики и точностных движений в спортивных играх / С.В. Голомазов, А.В. Ивойлов. - М., 2003. - 23 С., С. 20-23.

8. Донской Д.Д., Зациорский В.М. Три вида координации движений. - В кн.: Биомеханика. - М.: 1979. - С.28.

9. Евсеев С.П. Теория и организация адаптивной физической культуры. Том 1. М.: Советский спорт, 2007. — 291с.

10. Ильин Е.П. Ловкость - миф и реальность? // Теория и практика физической культуры, 1982. № 3 - С.48.

11. Карпеев А.Г. Двигательная координация человека в спортивных упражнениях баллистического типа. - Монография. - Омск: СибГАФК, 1998. - $324 c$.

12. Лях В.И. Координационные способности: диагностика и развитие. - М.: ТВТ Дивизион, 2006. - 290с.

13. Назаров В.П. Координация движений у детей школьного возраста. - М.: ФкиС, 1969. - 32С.

14. Рыцарев В.В. Волейбол: попытка причинного истолкования приёмов игры и процесса подготовки волейболистов / В.В. Рыцарев. — М.: Книга и бизнес, 2005. - 381c.

15. Шнейдер В.Ю. Методика обучения игре в волейбол: пособие для факультетов физической культуры. М.: Олимпия: Человек, 2009. $56 c$.

16. Шнейдер В.Ю. Психологические условия развития компетентности будущих тренеров, как организаторов инновационной стратегии обучения волейболу / В.Ю. Шнейдер, В.Ю. Лосев // Теория и практика физической культуры. 2015. № 11. С.89.

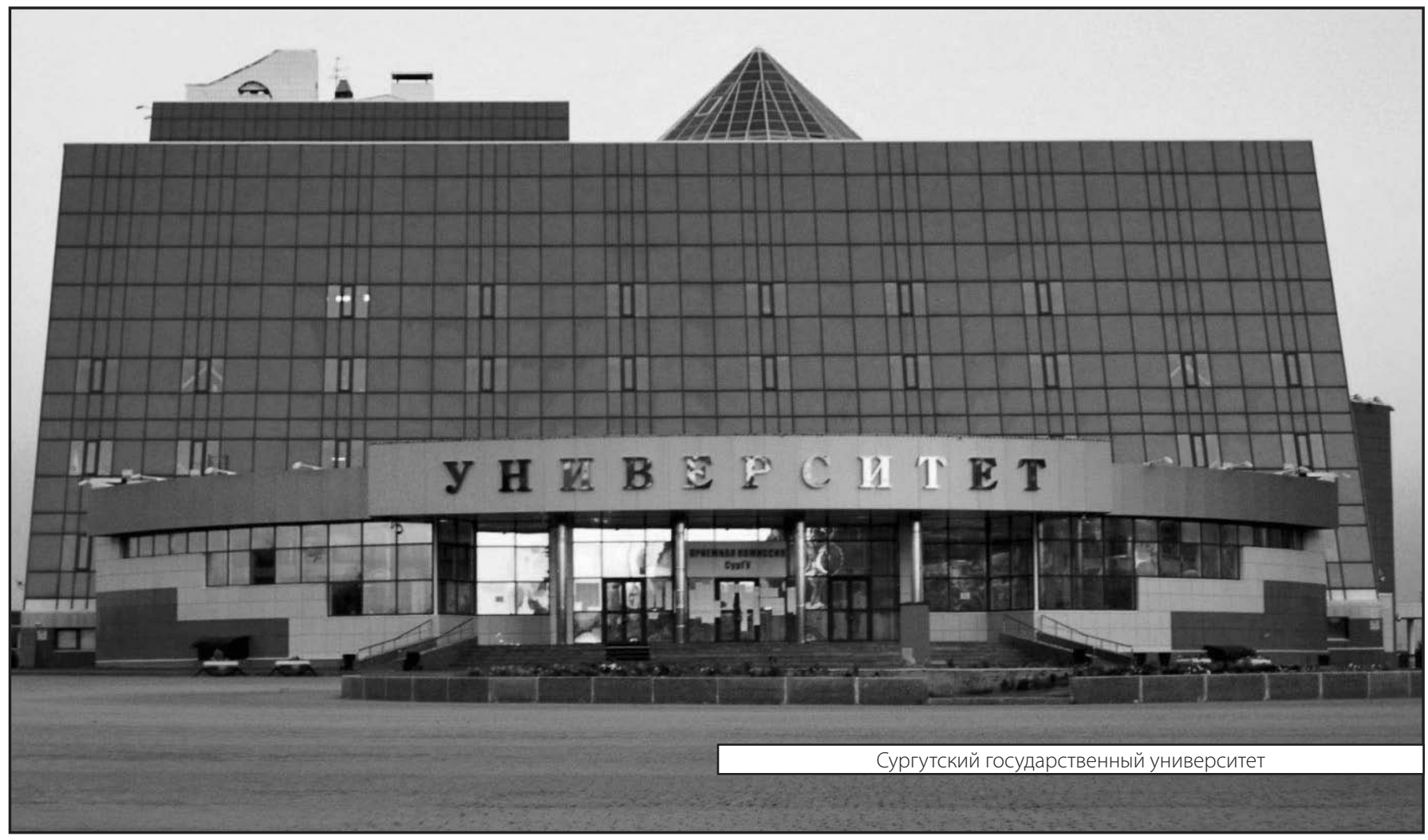

